\title{
FLUOROQUINOLONES IN THE WENYU RIVER CATCHMENT, CHINA: OCCURRENCE SIMULATION AND RISK ASSESSMENT
}

\author{
Xuewen Hao,$\dagger$ Yan CaO,$\dagger$ Lai Zhang, $†$ Yongyong Zhang, $\ddagger$ and Jianguo LiU* $* \dagger$ \\ $\dagger$ State Key Joint Laboratory of Environmental Simulation and Pollution Control, College of Environmental Sciences and Engineering, Peking University, \\ Beijing, People's Republic of China \\ $\ddagger$ Key Laboratory of Water Cycle and Related Land Surface Processes, Institute of Geographic Sciences and Natural Resources Research, Chinese \\ Academy of Sciences, Beijing, People's Republic of China
}

(Submitted 7 November 2014; Returned for Revision 2 March 2015; Accepted 7 July 2015)

\begin{abstract}
Concern is increasing regarding the environmental impact of the high usage rate and intensive release of antibiotics used for human and animal therapy in major urban areas of China. In the present study, regional environmental distribution simulations and risk assessments for 3 commonly used fluoroquinolones in the Wenyu River catchment were conducted using a typical catchment model widely used in Europe. The fluoroquinolone antibiotics investigated (ofloxacin, norfloxacin, and ciprofloxacin) are consumed at high levels for personal health care in China. These antibiotics were simulated in the aquatic environment of the Wenyu River catchment across the Beijing City area for annual average concentrations, with regional predicted environmental concentrations (PECs) of approximately $711 \mathrm{ng} / \mathrm{L}, 55.3 \mathrm{ng} / \mathrm{L}$, and $22.2 \mathrm{ng} / \mathrm{L}$ and local PECs up to $1.8 \mu \mathrm{g} / \mathrm{L}, 116 \mathrm{ng} / \mathrm{L}$, and $43 \mathrm{ng} / \mathrm{L}$, respectively. Apart from hydrological conditions, the concentrations of fluoroquinolones were associated closely with the sewage treatment plants (STPs) and their serving population, as well as hospital distributions. The presence of these fluoroquinolones in the catchment area of the present study showed significant characteristics of the occurrence of pharmaceuticals in the aquatic environment in an urban river, with typical "down-the-drain" chemicals. Significantly high concentrations of specific antibiotics indicated non-negligible risks caused by the intensive use in the local aquatic environment in a metropolitan area, particularly ofloxacin in upstream Shahe Reservoir, middle stream and downstream Qing River, and Liangma River to the Ba River segment. Specific treatment measures for these pharmaceuticals and personal care products in STPs are required for such metropolitan areas. Environ Toxicol Chem 2015;34:2764-2770. (C) 2015 SETAC
\end{abstract}

Keywords: Pharmaceuticals and personal care products (PPCPs) Fluoroquinolones $\quad$ GREAT-ER Risk assessment

\section{INTRODUCTION}

The environmental risks of pharmaceuticals and personal care products (PPCPs) have drawn increasing global attention because of their continuous release into the aquatic environment through sewage treatment plants (STPs), which may introduce environmental risks and harm the ecosystem [1]. Antibiotics commonly used in human and animal therapy are typically PPCPs and are estimated to be consumed at approximately 100000 tons to 200000 tons per year worldwide [2,3]. At least 25000 tons of antibiotics are consumed in China [4]. According to data from the World Health Organization, China has become the largest antibiotic consuming country, with per capita annual consumption of 138 grams, which is 10 -fold higher than in the United States. Moreover, the usage rate of antibiotics can reach $80 \%$ for hospitalized patients in China, where multiple-use and broad-spectrum antibiotics accounted for 58\%, which is far higher than the $30 \%$ international average [5]. The high antibiotic consumption in China is becoming an important issue.

Fluoroquinolones are among the most frequently used antibiotics in China, contributing to approximately $15 \%$ of human and livestock treatment in the country [6]. After incomplete metabolism in the human and animal body, components of fluoroquinolones are excreted unchanged through the urine and eventually enter the aquatic environment through STPs [1,7-9]. Fluoroquinolones have been detected in

All Supplemental Data may be found in the online version of this article.

* Address correspondence to jgliu@pku.edu.cn

Published online 14 July 2015 in Wiley Online Library

(wileyonlinelibrary.com).

DOI: $10.1002 /$ etc. 3158 the aquatic environment globally with concentrations from $10 \mathrm{~s}$ to 1000 s of nanograms per liter [10-13]. Meanwhile, numerous adverse effects of fluoroquinolones on the aquatic ecosystem have been reported, such as inducing antibiotic resistance in bacteria $[14,15]$, interfering with plant photochemical synthesis processes, and inhibiting plant growth [16]. In addition, genetic toxicity is a major concern [17-19].

In China in 2002, ofloxacin, norfloxacin, and ciprofloxacin accounted for $98 \%$ of the total fluoroquinolone production, with an annual production of 1200 tons, 3600 tons, and 1800 tons, respectively [20]. Thus, possible overload of these fluoroquinolones in regional aquatic ecosystems caused by intensive use and release from nearby metropolitan areas is of reasonable concern. In recent years, ofloxacin, norfloxacin, and ciprofloxacin have been detected at levels from 10s to 100s of nanograms per liter in surface water, including the Yellow River and Pearl River in China [6,21,22]. However, with limited monitoring studies, it is difficult to reflect regional distributions and risk profiles of fluoroquinolones spatially and temporally.

\section{MATERIALS AND METHODS}

\section{Model description}

In the present study, we conducted regional environmental distribution simulations and risk assessments for 3 commonly used fluoroquinolones in the Wenyu River catchment, using the most recent version of the Geography referenced Regional Exposure Assessment Tool for European Rivers (GREAT-ER) [23]. This tool is a typical catchment model widely used in Europe to simulate "down-the-drain" PPCPs and is available for worldwide application. It is an aquatic chemical exposure 
prediction and risk assessment tool and was developed to simulate and predict environmental concentrations of "downthe-drain" chemicals, typically PPCPs intensively discharged into rivers through STPs. The original GREAT-ER was developed to provide spatially predicted aquatic environmental concentrations with a colored geographic information systems map [24-26]. Then, GREAT-ER was upgraded to version 2.0, in which a database management system was combined with chemical, environment, and emission modules [27,28]. Compared with the earlier version, the unique property of GREATER version 3.0 is that open scenario siting is designed for public application outside of Europe.

The GREAT-ER system was designed in a modular way, consisting of geographic information systems data manipulation, hydrology, waste pathways, and river modeling, as well as end-use desktop geographic information systems [24-26]. The digital river network with predicted environmental concentrations (PECs) provides simulated output based on input data involving geography, hydrology, STPs, emission information, and other data sources of a specific chemical and catchment $[27,28]$. Considering parameter uncertainty, the Monte Carlo approach was used to conduct probabilistic simulations by randomly selecting input parameters for each run [28-30]. During the development phase, the model has proven to be stable and reliable by principle analysis and monitoring verification [24,31]. The model has been applied successfully to a variety of PPCPs (e.g., Linear Alkylbenzene Sulfonate, diclofenac, triclosan, aspirin, and $\beta$-blockers) in several European rivers, such as the Ruhr River Basin [29], the Itter catchment [32], the River Aire [27,33-34], the Llobregat River Basin [35], and the Glatt Valley watershed [36] showing its applicability and reliability. In the present study, GREAT-ER Ver 3.0 [23] was used for a localized application in the Wenyu River in China.

\section{Catchment building of the Wenyu River}

As a river flowing through parts of northeast Beijing, the Wenyu River is the ultimate water receiver of municipal wastewater containing down-the-drain chemicals (Figure S1). The Wenyu River originates in the Jundu Mountain of the Changping District and runs from the Shahe Reservoir to Beiguan Gate, with a main stream length of approximately $47.5 \mathrm{~km}$ and an entire drainage area of approximately $2478 \mathrm{~km}^{2}$. Three tributaries, Beisha River, Nansha River, and Dongsha River, meet at the upper reaches of the Wenyu River, and the Lingou River, Qing River, Ba River, and other tributaries are located downstream (Table S3). The Wenyu River lies in an area with forests, agriculture, and urban as its main land uses [37], without intensive livestock farming in most areas, because concentrated animal farms were prohibited within the Sixth Ring of Beijing [38,39]. The sixth ring is the outmost ring road containing the urban land use area [40].

A digital river network was established combined with hydrological data and emission information collected from previous studies to build the Wenyu River catchment (Figure 1). Geographic location, operating conditions, serving population, and other STP information was obtained using surveys (Table S4). Meanwhile, the only available hydrological data was referred to as runoff flows of the Wenyu River catchment simulated by the Soil and Water Assessment Tool [37], a hydrology and water quality model. The outlet flows of subbasin in Soil and Water Assessment Tool were used to build hydrologic data for each river section using GREAT-ER. In the present study, when simulating hydrological data using the
Soil and Water Assessment Tool, the total river length of model extraction is $398.04 \mathrm{~km}$. The resolution of the digital elevation map is $90 \mathrm{~m} \times 90 \mathrm{~m}$.

\section{Key parameters for modeling}

Chemical information. Due to insufficient experimental data for fluoroquinolones, most data on the physical and chemical properties of fluoroquinolones required for the modeling are either unavailable or inconsistent. The chemical property data of the 3 fluoroquinolones for modeling in the present study were obtained mainly by using the Estimation Program Interface Suite developed by the US Environmental Protection Agency's (USEPA) Office of Pollution Prevention Toxics and Syracuse Research. However, some experimental data were used when it was available from the literature. The chemical information with related data used in the present study are shown in the Supplemental Data, Table S1.

Wastewater treatment plant removal efficiency. The STP removal efficiencies of antibiotics have been reported widely and reviewed recently, with a focus on ofloxacin, norfloxacin, and ciprofloxacin. However, removal efficiencies differed with a wide range of $40 \%$ to $82 \%$ for ofloxacin, $50 \%$ to $92 \%$ for norfloxacin, and $66 \%$ to $90 \%$ for ciprofloxacin [6,41-51]. Activated sludge treatment has been investigated as a primary process in STPs in the Wenyu River catchment. Removal efficiencies through activated sludge treatment reported in previous studies are summarized in the Supplemental Data, Table S2. According to previous reports, the STP removal efficiencies for ofloxacin, norfloxacin, and ciprofloxacin averaged $62 \%, 70 \%$, and $73 \%$, respectively.

River removal rate. To date, the degradation studies on ofloxacin, norfloxacin, and ciprofloxacin in surface water are limited. Although photolysis half-lives of ofloxacin (10.6 d), norfloxacin (25.4-22.5 d), and ciprofloxacin (25.7-20.4 d) under laboratory conditions have been studied [52,53], information on river removal rates is limited. The present study simulated the half-life times using the Estimation Program Interface Suite model, and then calculated the removal rates in the aquatic environment. In the present study, the ultimately selected removal rates of ofloxacin, norfloxacin, and ciprofloxacin in the aquatic environment were $1.60 \mathrm{E}-4 \mathrm{~h}^{-1}, 4.81 \mathrm{E}-4 \mathrm{~h}^{-1}$, and $4.81 \mathrm{E}-4 \mathrm{~h}^{-1}$, respectively.

Emission data. Statistical data on the consumption of fluoroquinolones at the city and national level in China are unavailable. Thus, in the present study, the direct emissions from STPs were considered as the actual annual personal capita consumptions for the 3 fluoroquinolones. These were calculated according to influent concentrations, influent flows, and residential population served by STPs based on the study by Gao et al. [48], in which concentrations of 22 antibiotics were detected in 8 STPs in Beijing. As a result, annual per capita consumptions were $2.29 \mathrm{E}-4 \mathrm{~kg} / \mathrm{cap}$ year, $2.18 \mathrm{E}-5 \mathrm{~kg} / \mathrm{cap}$ year, and $9.70 \mathrm{E}-6 \mathrm{~kg} / \mathrm{cap}$ year for ofloxacin, norfloxacin, and ciprofloxacin, respectively.

\section{RESULTS AND DISCUSSION}

\section{Predicted environmental concentrations}

Environmental concentrations of ofloxacin, norfloxacin, and ciprofloxacin in the Wenyu River catchment were predicted using the GREAT-ER model. Results showed simulated concentrations both at the regional scale (PEC catchment) and the local scale (PEC initial). The PEC catchment represented the overall concentrations in the Wenyu River 


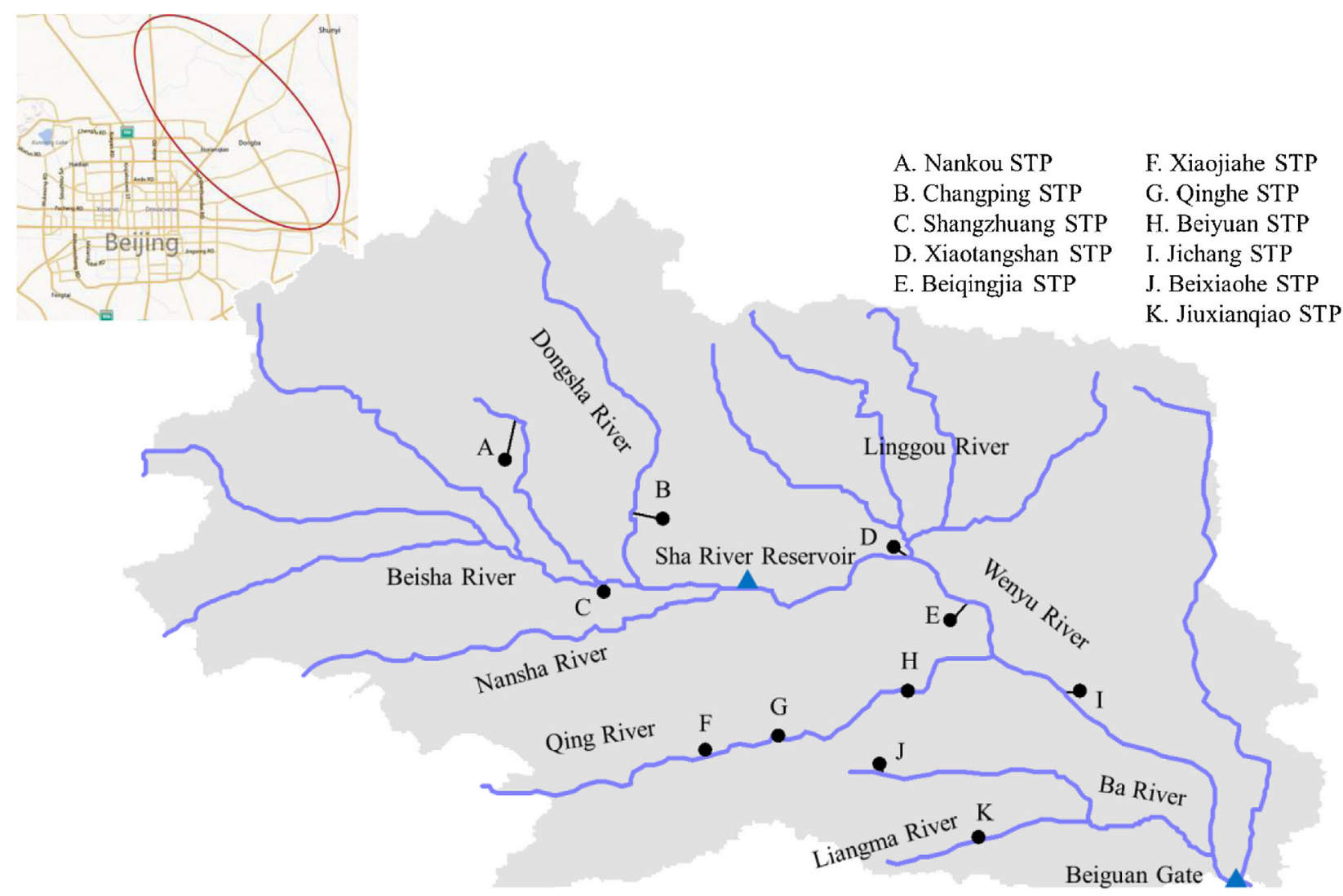

Figure 1. The Wenyu River catchment. STP = sewage treatment plant.

catchment, which was the average concentration over all river stretches downstream of the STPs. The PEC initial represented the spatial aggregation of concentrations in the river directly after emission, which was defined as the average predicted environmental concentration downstream of the emission point source after initial dilution [26,27]. In the present study, the PEC catchment of ofloxacin, norfloxacin, and ciprofloxacin at a regional scale were $711 \mathrm{ng} / \mathrm{L}, 55.3 \mathrm{ng} / \mathrm{L}$, and $22.2 \mathrm{ng} / \mathrm{L}$, whereas PEC initial were $1.8 \mu \mathrm{g} / \mathrm{L}, 116 \mathrm{ng} / \mathrm{L}$, and $43 \mathrm{ng} / \mathrm{L}$, respectively. Compared with monitoring concentrations of ofloxacin, norfloxacin, and ciprofloxacin that were $25.1 \mathrm{ng} / \mathrm{L}$ to $1213.6 \mathrm{ng} / \mathrm{L}$, not detected (nd) to $<199.4 \mathrm{ng} / \mathrm{L}$, and nd to $<24.1 \mathrm{ng} / \mathrm{L}$, respectively (Q.Q. Zhang, 2012, Master's thesis, Chongqing University, Chongqing, China), the predicted concentrations at the regional scale were consistent with monitoring concentrations, indicating that the simulated results were acceptable.

Compared with reported environmental concentrations of fluoroquinolones nationwide in recent years, the concentration of ofloxacin in the Wenyu River catchment was slightly higher than currently available monitoring results, whereas concentrations of norfloxacin and ciprofloxacin were comparable to other monitoring results $[22,44,47,54-58]$. The high residential population and number of hospitals in Beijing may explain these results.

On a global scale, the predicted concentration of ofloxacin in the Wenyu River catchment was the same magnitude as reported environmental concentrations in Osaka, Japan [12]; was higher than those in the Rhône-Alpes region in France [59], the Seine River in France [60], and the Po and Arno Rivers in Italy [61]; and lower than that in Llobregat River in Spain [62]. The concentrations of norfloxacin and ciprofloxacin were comparable to those of actual monitoring results in 139 streams in the
United States [10], 6 rivers in South East Queensland in Australia [63], the Seine River in France [60], the Po and Arno Rivers in Italy [61], and the Glatt Valley Watershed in Switzerland [41]. Thus, fluoroquinolone pollution in the Wenyu River catchment is relatively serious and is associated with the high antibiotic consumption rate in the region. Although current pollution concentrations for fluoroquinolones in the Wenyu River catchment were comparable on the global level, much more attention should be paid to other major cities in China similar to Beijing with large urban populations and high antibiotic consumptions, where much more serious pollution statuses could occur in rivers across the selected study city.

\section{Fluoroquinolone distribution}

Predicted concentrations of fluoroquinolones throughout the Wenyu River catchment are shown in Figure 2. Concentration variations with the downstream distance for ofloxacin, norfloxacin, and ciprofloxacin from the Shahe Reservoir to the Beiguan Gate (including the Wenyu main stream) are shown in Figure 3. We found that ofloxacin presented at the highest concentration, followed by norfloxacin, and ciprofloxacin, whose concentrations differed from each other by 1 order of magnitude. Distribution trends of the 3 fluoroquinolones were similar in the Wenyu River catchment, which showed that upstream of the Shahe Reservoir, middle stream and downstream of the Qing River, and the Liangma River to the Ba River segment contained high concentrations. Concentrations of ofloxacin, norfloxacin, and ciprofloxacin reached $1700 \mathrm{ng} / \mathrm{L}, 730 \mathrm{ng} / \mathrm{L}$, and $266 \mathrm{ng} / \mathrm{L}$ upstream from Shahe Gate; $1400 \mathrm{ng} / \mathrm{L}$ to $2400 \mathrm{ng} / \mathrm{L}, 98 \mathrm{ng} / \mathrm{L}$ to $167 \mathrm{ng} / \mathrm{L}$, and $39 \mathrm{ng} / \mathrm{L}$ to $66 \mathrm{ng} / \mathrm{L}$ in the middle stream and downstream of the Qing River, and $1600 \mathrm{ng} / \mathrm{L}$ to $2200 \mathrm{ng} / \mathrm{L}$, $110 \mathrm{ng} / \mathrm{L}$ to $155 \mathrm{ng} / \mathrm{L}$, and $44 \mathrm{ng} / \mathrm{L}$ to $62 \mathrm{ng} / \mathrm{L}$ in the Liangma 


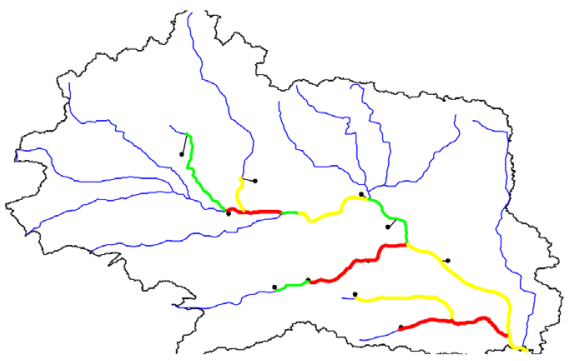

Ofloxacin

Csim mean $[\mathrm{ug} / \mathrm{L}]$

$$
\begin{aligned}
& 0.0-0.50 \\
& 0.50-1.5 \\
& >1.5
\end{aligned}
$$

River network

$\Upsilon^{\prime}$ Default

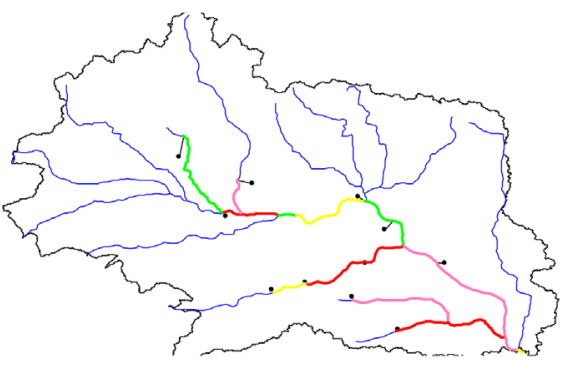

Norfloxacin

Csim mean $[\mathrm{ng} / \mathrm{L}]$

$0.0-20$

$20-80$

$80-110$

$>110$

River network

$\checkmark$ Default

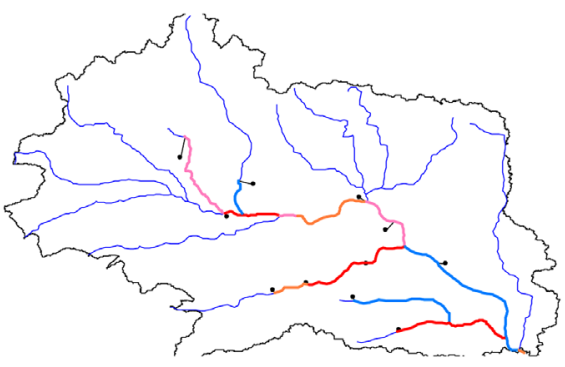

\section{Ciprofloxacin}

Csim mean $[\mathrm{ng} / \mathrm{L}]$

0.0-10

10-30

30-45

$\mu>45$

River network

$\sim$ Default

Figure 2. Predicted concentrations of fluoroquinolones in the Wenyu River catchment. The black dots represent the locations of discharge sites, whereas the river networks are indicated by fine blue lines.

River to the Ba River segment, respectively. Hydrologic features and STP discharge situations could explain the reaches with higher concentrations, as follows.

Upstream from Shahe Gate is the confluence of the Dongsha River, Huyu stream, Nansha River, and Beisha River. Mass fluxes were simulated based on stream flows, STP discharges, and concentrations of the 3 fluoroquinolones in upstream tributaries, which showed that the mass flux of ofloxacin

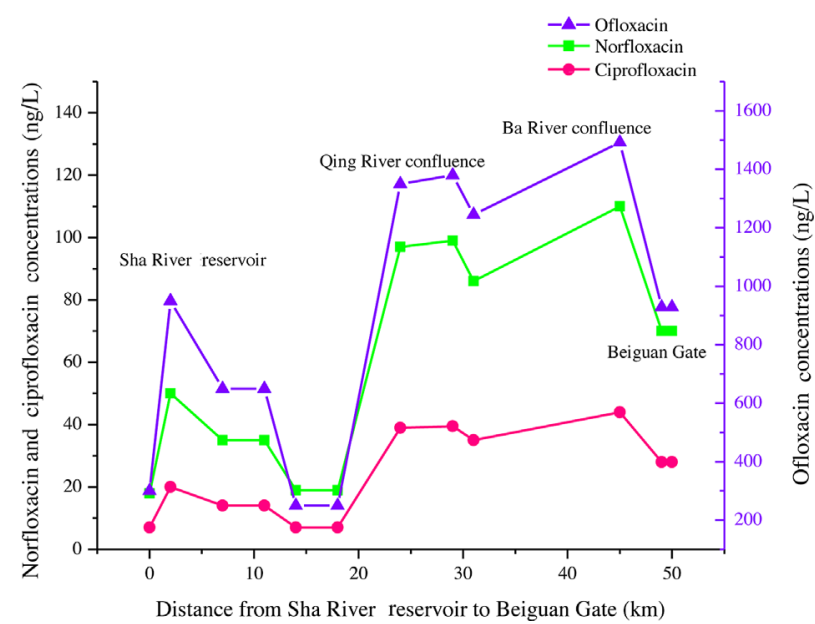

Figure 3. Predicted concentrations from the Sha River Reservoir to Beiguan Gate. upstream of the Shahe Reservoir $(0.873 \mathrm{ng} / \mathrm{s})$ was greater than that in upstream tributaries such as the Dongsha River $(0.378 \mathrm{ng} / \mathrm{s})$ and Huxia stream $(0.0900 \mathrm{ng} / \mathrm{s})$. Norfloxacin and ciprofloxacin showed a similar situation. Thus, ofloxacin, norfloxacin, and ciprofloxacin were present at high concentrations upstream of the Shahe Reservoir.

The 2 main tributaries, Qing River and Ba River, flow into the Wenyu River. The Xiaojiahe STP, Qinghe STP, and Beiyuan STP are situated on the Qinghe River, and the Jiuxianqiao STP is located on the Liangma River, upstream of the Bahe River. Among these STPs in simulated scenarios of the Wenyu River catchment, the Qinghe STP is the largest STP serving a residential population of approximately 2570000 with an average domestic wastewater flow of $450000 \mathrm{~m}^{3} / \mathrm{d}$. Furthermore, the Xiaojiahe STP and Beiyuan STP located in the Qing River serve a population of approximately 114000 and 234000 , respectively. As the second largest STP, the Jiuxianqiao STP serves a population of approximately 1160000 and treats approximately $203000 \mathrm{~m}^{3} / \mathrm{d}$ of municipal wastewater. Based on the STP locations, we can infer that because multiple large STPs are situated on the Qing River and from the Liangma River to the Ba River segment with a large population and daily treatment capacity, their larger emission increases concentrations of fluoroquinolones compared with other river reaches.

Furthermore, by investigating hospital distributions in the Wenyu River catchment (Table S5), a majority of large and medium-sized hospitals are located on these river reaches with nearly 20 hospitals on the Liangma River to the Ba River segment, almost 15 hospitals on the Qing River, and more than 5 hospitals on Sha River, which are shown in the Supplemental Data, Figure S2. As predominant sources of antibiotics, wastewater from hospitals is generally discharged into municipal wastewater treatment plants after primary treatment $[64,65]$, (L.L. Lu, 2010, Master's thesis, Jinan University, Guangdong, China), which could increase fluoroquinolone concentrations in river reaches, the ultimate water receiver of municipal wastewater. These 3 river reaches with high concentrations were also in accordance with high-density hospital distributions. As shown in Figure 3, peak concentrations of ofloxacin, norfloxacin, and ciprofloxacin occur approximately $24 \mathrm{~km}$ and $46 \mathrm{~km}$ from Sha River Gate to Beiguan Gate, respectively, where the Qing River and Ba River separately flow into the Wenyu main stream. Thus, higher concentrations of ofloxacin, norfloxacin, and ciprofloxacin exist in the Qing River and $\mathrm{Ba}$ River.

Based on the actual situation and the simulation in the present study, the high concentration regions, such as those in the Qing River and $\mathrm{Ba}$ River, are related to both densely populated areas and dense hospital distributions. Besides hydrological conditions and river flows, concentrations of fluoroquinolones in rivers were associated with the serving population and hospital usage. In the context of the large consumption of antibiotics in China, such an urban river catchment could present non-negligible risks caused by the intensive use of antibiotics by dense population in metropolis areas.

\section{Environmental risk assessment}

The ratio of PEC to predicted no effect concentrations (PNEC) was used as a method to characterize the environmental risk. If the ratio were greater than 1 , it posed a potential risk in the regional environment. The PNEC can be extrapolated from acute and chronic toxicity data for the most sensitive species by applying 

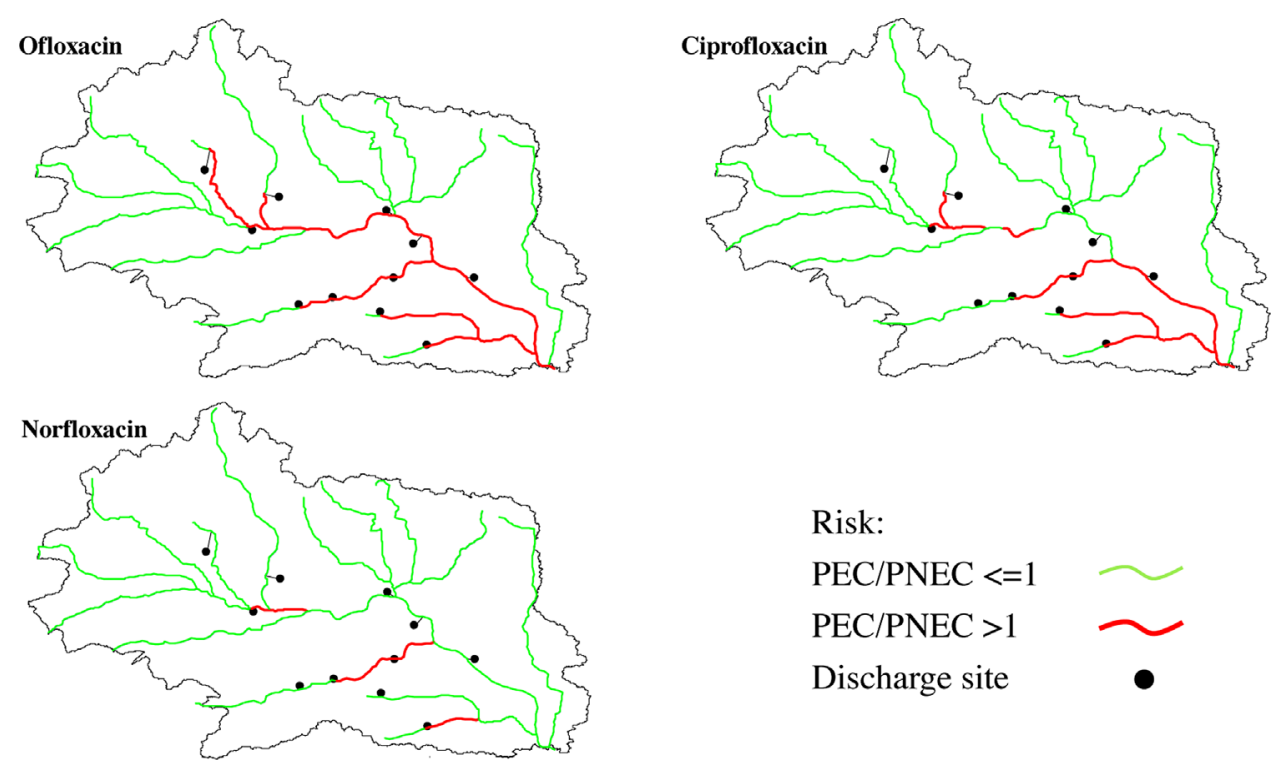

Risk:

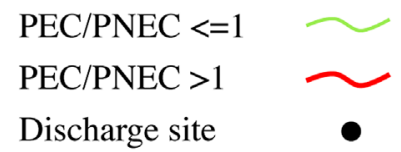

Figure 4. Environmental risks in the Wenyu River catchment. PEC $=$ predicted environmental concentrations; PNEC $=$ predicted no-effect concentrations.

assessment factors according to different situations. In the present study, algae and invertebrates were relatively susceptible to antibiotics [66]. For acute toxicity, 50\% effective concentrations (EC50s) were divided by a factor of 1000 . For chronic toxicity, chronic no effect concentrations (NOECs) were divided by a factor of 100 or 10 [67,68]. In addition, the PNEC can be obtained from the USEPA's Ecological Structure Activity Relationships (ECOSAR) model [69]. Based on available studies, PNECs for ofloxacin, norfloxacin, and ciprofloxacin were used in the present study, which were $0.016 \mu \mathrm{g} / \mathrm{L}$ [70], 0.15- $\mu \mathrm{g} / \mathrm{L}$ [71], and $0.02 \mu \mathrm{g} /$ L [71], respectively.

The predicted results are shown in Figure 4. The red line indicates that the ratio of PEC to PNEC is higher than 1, which represents potential environmental risks. Besides, the green line indicates that the PEC or PNEC is lower than 1, which represents low environmental risks. Based on Figure 4, ofloxacin poses risks to all of the Wenyu River catchment. Norfloxacin shows risks in the Sha River, Qing River, and Ba River. Ciprofloxacin shows risks in the Sha River, Qing River, $\mathrm{Ba}$ River, and the Wenyu main stream. Overall, regions downstream of intensive emission areas are at high risk.

\section{Uncertainties}

Within the stochastic approach in the model, there remains some degree of uncertainty, for example, catchment building processes, emission inventories, and parameters. For the catchment building process, because the aquatic chemical exposure prediction and risk assessment tool, GREAT-ER was originally designed for European rivers, with default catchment in Europe, key factors such as the precision of the digital river network, the sufficiency of hydrological data and emission information could have impacts on the simulated results in China. Compared with Europe, the scenario-building process in the present study is not sufficiently advanced to narrow the gap between simulation and the actual situation. In addition, because of the lack of reliable emission inventories in China, releases of the 3 fluoroquinolones per capita within the Wenyu River catchment were calculated values instead of statistical data, and untreated discharges of the 3 fluoroquinolones were not included in the present study, which would bring about differences from the actual situation. Besides, due to the lack of degradation and toxicology data of fluoroquinolones, input parameters such as STPs removal efficiency and river removal rate were obtained from literature data, with limited information or considerable variation in different studies, which might lead to uncertainty in the model results. In conclusion, more reasonable and accurate background information is required to further refine the localized application of GREAT-ER in China in future studies.

\section{CONCLUSIONS}

A widespread occurrence of 3 typical fluoroquinolones, namely, ofloxacin, norfloxacin, and ciprofloxacin, was detected in the aquatic environment of the Wenyu River catchment across the Beijing City area in China. Fluoroquinolone concentrations were associated with the distribution of STPs and their serving population, as well as hospital distributions, showing significant features of the typical kind of "down-thedrain" chemicals in the aquatic environment of an urban river. As a type of large-scale consumption antibiotic for personal health care in China, fluoroquinolones showed relatively high concentrations compared with other national and international reports, indicating non-negligible environmental risks of this typical kind of PPCPs to the local aquatic environment in a metropolitan area, particularly ofloxacin in upstream Shahe Reservoir, middle stream and downstream Qing River, and from the Liangma River to the Ba River segment. Specific treatment measures for these PPCPs in STPs are required for such a kind of metropolitan area.

\section{SUPPLEMENTAL DATA}

Tables S1-S5.

Figures S1-S2. (529 KB DOC).

Acknowledgment-This project is supported by the State Key Joint Laboratory of Environment Simulation and Pollution Control (Peking University) which provided funding and assistance, and with support from the National Science Foundation of China (No. 21206011); and The Importation and Development of High-Caliber Talents Project of Beijing Municipal Institutions; The National Basic Research Program of China (No. IDHT201304084). The authors also thank J. Wang, Master's degree student from College of Environmental Sciences and Engineering, Peking University, China for his kind help in information searching. 
Data availability-Data, associated metadata, and calculation tools are available from the author (jgliu@pku.edu.cn).

\section{REFERENCES}

1. Daughton CG, Ternes TA. 1999. Pharmaceuticals and personal care products in the environment: Agents of subtle change? Environ Health Perspect 107:907-938.

2. Kummerer K. 2003. Significance of antibiotics in the environment. J Antimicrob Chemoth 52:5-7.

3. Richardson SD, Ternes TA. 2005. Water analysis: Emerging contaminants and current issues. Anal Chem 77:3807-3838.

4. Yi RH, Wang QJ, Mo CH, Li YW, Gao P, Tai YP, Zhang Y, Ruan ZL, $\mathrm{Xu}$ JW. 2010. Determination of four fluoroquinolone antibiotics in tap water in Guangzhou and Macao. Environ Pollut 158:2350-2358.

5. World Economic Forum. 2013. Global Risks 2013, 8th ed. Geneva, Switzerland.

6. Xu W, Zhang G, Li X, Zou S, Li P, Hu Z, Li J. 2007. Occurrence and elimination of antibiotics at four sewage treatment plants in the Pearl River Delta (PRD), South China. Water Res 41:4526-4534.

7. Renew JE, Huang CH. 2004. Simultaneous determination of fluoroquinolone, sulfonamide, and trimethoprim antibiotics in wastewater using tandem solid phase extraction and liquid chromatographyelectrospray mass spectrometry. J Chromatogr A 1042:113-121.

8. Dodd MC, Shah AD, von Gunten U, Huang CH. 2005. Interactions of fluoroquinolone antibacterial agents with aqueous chlorine: Reaction kinetics, mechanisms, and transformation pathways. Environ Sci Technol 39:7065-7076.

9. Mitani K. 2006. Determination of fluoroquinolones in environmental waters by in-tube solid-phase microextraction coupled with liquid chromatography-tandem mass spectrometry. Anal Chim Acta 562:16-22.

10. Kolpin DW, Furlong ET, Meyer MT, Thurman EM, Zaugg SD, Barber LB, Buxton HT. 2002. Pharmaceuticals, hormones, and other organic wastewater contaminants in U.S. streams, 1999-2000: A national reconnaissance. Environ Sci Technol 36:1202-1211.

11. Nakata H, Kannan K, Jones PD, Giesy JP. 2005. Determination of fluoroquinolone antibiotics in wastewater effluents by liquid chromatography-mass spectrometry and fluorescence detection. Chemosphere 58:759-766.

12. Adachi F, Yamamoto A, Takakura K, Kawahara R. 2013. Occurrence of fluoroquinolones and fluoroquinolone-resistance genes in the aquatic environment. Sci Total Environ 444:508-514.

13. Bu Q, Wang B, Huang J, Deng S, Yu G. 2013. Pharmaceuticals and personal care products in the aquatic environment in China: A review. $J$ Hazard Mater 262:189-211.

14. Neu HC. 1992. The crisis in antibiotic resistance. Science 257:1064-1073.

15. Huber MM, Gobel A, Joss A, Hermann N, Loffler D, McArdell CS, Ried A, Siegrist H, Ternes TA, von Gunten U. 2005. Oxidation of pharmaceuticals during ozonation of municipal wastewater effluents: A pilot study. Environ Sci Technol 39:4290-4299.

16. Aristilde L, Melis A, Sposito G. 2010. Inhibition of photosynthesis by a fluoroquinolone antibiotic. Environ Sci Technol 44:1444-1450.

17. Hartmann A, Alder AC, Widmer RM. 1998. Identification of fluoroquinolone antibiotics as the main source of $и т и C$ genotoxicity in native hospital wastewater. Environ Toxicol Chem 17:377-382.

18. Hu J, Wang W, Zhu Z, Chang H, Pan F, Lin B. 2007. Quantitative structure-activity relationship model for prediction of genotoxic potential for quinolone antibacterials. Environ Sci Technol 41:4806-4812.

19. Khadra A, Pinelli E, Lacroix MZ, Bousquet-Melou A, Hamdi H, Merlina G, Guiresse M, Hafidi M. 2012. Assessment of the genotoxicity of quinolone and fluoroquinolones contaminated soil with the Vicia faba micronucleus test. Ecotoxicol Environ Safe 76:187-192.

20. Lv YM. 2004. Market analysis and development prospects of fluoroquinolones. China Chemicals 5:23-25 (in Chinese).

21. Xu WH, Zhang G, Zou SC, Li XD, Liu YC. 2007. Determination of selected antibiotics in the Victoria Harbour and the Pearl River, South China using high-performance liquid chromatography-electrospray ionization tandem mass spectrometry. Environ Pollut 145: 672-679.

22. Xu W, Zhang G, Zou S, Ling Z, Wang G, Yan W. 2009. A preliminary investigation on the occurrence and distribution of antibiotics in the Yellow River and its tributaries, China. Water Environ Res 81:248-254.

23. Geography referenced Regional Exposure Assessment Tool for European Rivers. [cited 2015 April 6]. Available from: www.greater.org.
24. Boeije G, Vanrolleghem P, Matthies M. 1997. A geo-referenced aquatic exposure prediction methodology for "down-the-drain" chemicals. Water Sci Technol 36:251-258.

25. Feijtel T, Matthies M, Morris G, Hansen B, Holt M, Schroder R, Schowanek D, Niessen H. 1997. Development of a geographyreferenced regional exposure assessment tool for European rivers: GREAT-ER contribution to GREAT-ER \#1. Chemosphere 34:2351-2373.

26. Boeije GM, Wagner JO, Vanrolleghem PA, Feijtel T. 2000. New PEC definitions for river basins applicable to GIS-based environmental exposure assessment. Chemosphere 40:255-265.

27. Schowanek D, Webb S. 2002. Exposure simulation for pharmaceuticals in European surface waters with GREAT-ER. Toxicol Lett 131:39-50.

28. Koormann F, Schowanek D, Schroder R, Silvani M. 2006. Modeling the fate of down-the-drain chemicals in rivers: An improved software for GREAT-ER. Environ Modell Soft 21:925-936.

29. Bester K, Hüffmeyer N, Schaub E, Klasmeier J. 2008. Surface water concentrations of the fragrance compound OTNE in Germany: A comparison between data from measurements and models. Chemosphere 73:1366-1372.

30. Hüffmeyer N, Klasmeier J, Matthies M. 2009. Geo-referenced modeling of zinc concentrations in the Ruhr river basin (Germany) using the model GREAT-ER. Sci Total Environ 407:2296-2305.

31. Fox KK, Daniel M, Morris G, Holt MS. 2000. The use of measured boron concentration data from the GREAT-ER UK validation study (1996-1998) to generate predicted regional boron concentrations. Sci Total Environ 251:305-316.

32. Wind T, Werner U, Jacob M, Hauk A. 2004. Environmental concentrations of boron, LAS, EDTA, NTA and triclosan simulated with GREAT-ER in the river Itter. Chemosphere 54:1145-1154.

33. Sabaliunas D, Webb SF, Hauk A, Jacob M, Eckhoff WS. 2003. Environmental fate of triclosan in the River Aire Basin, UK. Water Res 37:3145-3154.

34. Price OR, Munday DK, Whelan MJ, Holt MS, Fox KK, Morris G, Young AR. 2009. Data requirements of GREAT-ER: Modelling and validation using LAS in four UK catchments. Environ Pollut 157:2610-2616.

35. Aldekoa J, Medici C, Osorio V, Pérez S, Marcé R, Barceló D, Francés F. 2013. Modelling the emerging pollutant diclofenac with the GREATER model: Application to the Llobregat River Basin. J Hazard Mater 263:207-213.

36. Alder AC, Schaffner C, Majewsky M, Klasmeier J, Fenner K. 2010. Fate of beta-blocker human pharmaceuticals in surface water: Comparison of measured and simulated concentrations in the Glatt Valley Watershed, Switzerland. Water Res 44:936-948.

37. Zhang Y, Xia J, Chen J, Zhang M. 2011. Water quantity and quality optimization modeling of dams operation based on SWAT in Wenyu River catchment, China. Environ Monit Assess 173:409-430.

38. Li W, Li YX, Yang M, Dong YS, Han W, Zhang FS. 2010. Spatial distribution of livestock and poultry production and land application accessibility of animal manure in Beijing. J Nat Resour 25:746-755 (in Chinese).

39. Li YX, Xiong X, Lin CY, Zhang, FS, Li W, Han W. 2010. Cadmium in animal production and its potential hazard on Beijing and Fuxin farmlands. J Hazard Mater 177:475-480.

40. Yang J, Zhou JX. 2007. The failure and success of greenbelt program in Beijing. Urban Forestry \& Urban Greening 6:287-296.

41. Golet EM, Alder AC, Giger W. 2002. Environmental exposure and risk assessment of fluoroquinolone antibacterial agents in wastewater and river water of the Glatt Valley Watershed, Switzerland. Environ Sci Technol 36:3645-3651.

42. Castiglioni S, Bagnati R, Fanelli R, Pomati F, Calamari D, Zuccato E. 2006. Removal of pharmaceuticals in sewage treatment plants in Italy. Environ Sci Technol 40:357-363.

43. Vieno N, Tuhkanen T, Kronberg L. 2007. Elimination of pharmaceuticals in sewage treatment plants in Finland. Water Res 41:1001-1012.

44. Xiao Y, Chang H, Jia A, Hu J. 2008. Trace analysis of quinolone and fluoroquinolone antibiotics from wastewaters by liquid chromatography-electrospray tandem mass spectrometry. $J$ Chromatogr A 1214:100-108.

45. Zorita S, Martensson L, Mathiasson L. 2009. Occurrence and removal of pharmaceuticals in a municipal sewage treatment system in the south of Sweden. Sci Total Environ 407:2760-2770.

46. Li B, Zhang T. 2011. Mass flows and removal of antibiotics in two municipal wastewater treatment plants. Chemosphere 83:1284-1289.

47. Tong C, Zhuo X, Guo Y. 2011. Occurrence and risk assessment of four typical fluoroquinolone antibiotics in raw and treated sewage and in 
receiving waters in Hangzhou, China. $J$ Agric Food Chem 59:7303-7309.

48. Gao L, Shi Y, Li W, Niu H, Liu J, Cai Y. 2012. Occurrence of antibiotics in eight sewage treatment plants in Beijing, China. Chemosphere 86:665-671.

49. Jia A, Wan Y, Xiao Y, Hu J. 2012. Occurrence and fate of quinolone and fluoroquinolone antibiotics in a municipal sewage treatment plant. Water Res 46:387-394.

50. Li W, Shi Y, Gao L, Liu J, Cai Y. 2013. Occurrence and removal of antibiotics in a municipal wastewater reclamation plant in Beijing, China. Chemosphere 92:435-444.

51. Zhou LJ, Ying GG, Liu S, Zhao JL, Yang B, Chen ZF, Lai HJ. 2013. Occurrence and fate of eleven classes of antibiotics in two typical wastewater treatment plants in South China. Sci Total Environ 452453:365-376

52. Andreozzi R, Raffaele M, Nicklas P. 2003. Pharmaceuticals in STP effluents and their solar photodegradation in aquatic environment. Chemosphere 50:1319-1330.

53. Thi T, Loan T, Le NP, Dao QP, Trinh PH. 2012. Fate of fluoroquinolone antibiotics in Vietnamese coastal wetland ecosystem. Wetl Ecol Manag 20:399-408.

54. Peng X, Tan J, Tang C, Yu Y, Wang Z. 2008. Multiresidue determination of fluoroquinolone, sulfonamide, trimethoprim, and chloramphenicol antibiotics in urban waters in China. Environ Toxicol Chem 27:73-79.

55. Na GS, Gu J, Ge LK, Zhang P, Wang Z, Liu CY, Zhang L. 2011. Detection of 36 antibiotics in coastal waters using high performance liquid chromatography-tandem mass spectrometry. Chin. J Oceanol Limnol 29:1093-1102.

56. Yang JF, Ying GG, Zhao JL, Tao R, Su HC, Liu YS. 2011. Spatial and seasonal distribution of selected antibiotics in surface waters of the Pearl Rivers, China. J Environ Sci Heal B 46:272-280.

57. Zou S, Xu W, Zhang R, Tang J, Chen Y, Zhang G. 2011. Occurrence and distribution of antibiotics in coastal water of the Bohai Bay, China: Impacts of river discharge and aquaculture activities. Environ Pollut 159:2913-2920.

58. Gao L, Shi Y, Li W, Liu J, Cai Y. 2012. Occurrence, distribution and bioaccumulation of antibiotics in the Haihe River in China. J Environ Monitor 14:1248-1255.

59. Vulliet E, Cren-Olive C. 2011. Screening of pharmaceuticals and hormones at the regional scale, in surface and groundwaters intended to human consumption. Environ Pollut 159:2929-2934.
60. Tamtam F, Mercier F, Le Bot B, Eurin J, Tuc DQ, Clement M, Chevreuil M. 2008. Occurrence and fate of antibiotics in the Seine River in various hydrological conditions. Sci Total Environ 393:84-95.

61. Zuccato E, Castiglioni S, Bagnati R, Melis M, Fanelli R. 2010. Source, occurrence and fate of antibiotics in the Italian aquatic environment. J Hazard Mater 179:1042-1048.

62. Ginebreda A, Munoz I, de Alda ML, Brix R, Lopez-Doval J, Barcelo D. 2010. Environmental risk assessment of pharmaceuticals in rivers: Relationships between hazard indexes and aquatic macroinvertebrate diversity indexes in the Llobregat River (NE Spain). Environ Int 36:153-162.

63. Watkinson AJ, Murby EJ, Kolpin DW, Costanzo SD. 2009. The occurrence of antibiotics in an urban watershed: From wastewater to drinking water. Sci Total Environ 407:2711-2723.

64. Chen ZL, Ye MP. 2003. Progress in technology of hospital wastewater treatment. Environ Sci Technol 26:49-50 (in Chinese).

65. Li Z, Li M, Li Y, Prospere A. 2009. Experimental study on treatmental efficiency of wastewater from small hospital by vertical flow constructed wetland. Proceedings. IEEE International Conference on Management and Service Science, Wuhan, China, September 16-18, 2009, pp 1-4.

66. Leung HW, Minh TB, Murphy MB, Lam JC, So MK, Martin M, Lam PK, Richardson BJ. 2012. Distribution, fate and risk assessment of antibiotics in sewage treatment plants in Hong Kong, South China. Environ Int 42:1-9.

67. Sanderson H, Wilson CJ, Solomon KR. 2003. Probabilistic hazard assessment of environmentally occurring pharmaceuticals toxicity to fish, daphnids and algae by ECOSAR screening. Toxicol Lett 144:383-395.

68. Cunningham VL, Hutchinson T, Parke N. 2006. Effects of human pharmaceuticals on aquatic life: Next steps. Environ Sci Technol 40:3456-3462.

69. US Environmental Protection Agency. 2012. Ecological Structure Activity Relationships (ECOSAR) model. [cited 2015 April 18]. Available from: http://www.epa.gov/oppt/newchems/tools/21ecosar.htm.

70. Ferrari B, Vollat B, Paxeus N, Pollio A. 2004. Environmental risk assessment of six human pharmaceuticals: Are the current environmental risk assessment procedures sufficient for the protection of the aquatic environment? Environ Toxicol Chem 23:1344-1354.

71. Kummerer K. 2003. Promoting resistance by the emission of antibiotics from hospitals and households into effluent. Clin Microbiol Infect 9:1203-1214. 